\title{
Improving vehicle adaptability to the operating conditions of «smart» cities in the northern regions
}

\author{
Ilya Anisimov ${ }^{1 a}$, Elena Magaril ${ }^{2}$, Romen $_{\text {Magaril }}{ }^{3}$, Evgeniy Chikishev $^{1}$, Denis Chainikov ${ }^{1}$, \\ Aleksandr Gavaev ${ }^{1}$, Sergei Ertman ${ }^{1}$, Yuliya Ertman ${ }^{1}$, and Andrei Ivanov ${ }^{4}$ \\ ${ }^{1}$ Department of Motor Transport, Tyumen Industrial University, 625000, Tyumen, Russia \\ ${ }^{2}$ Research and Educational Centre ENGEC, Ural Federal University, 620002, Yekaterinburg, Russia \\ ${ }^{3}$ Department of Oil and Gas Processing, Industrial University of Tyumen, 625000, Tyumen, Russia \\ ${ }^{4}$ Technical systems in the agriculture, Northern Trans-Ural State Agricultural University, 625003, \\ Tyumen, Russia
}

\begin{abstract}
The paper reviews a relevant problem of providing a higher quality of people's living in the northern regions by the application of the modern technologies within transport in order to improve its environmental performance and efficiency. The aim of the research is to substantiate methods of increasing the adaptability of vehicles to variable low-temperature operating conditions based on a neural control system of preheating and maintaining the optimum temperature of technological fluids by SHF radiation and improving diesel fuel properties by introducing a multifunctional additive. It has been found that SHF radiation influences the physical and chemical parameters of diesel fuel, as well as the engine output parameters. SHF radiation results in a reduction of fuel consumption to $7 \%$, smoke from the exhaust to $15 \%$, and nitrogen oxide emission to $30 \%$. A conclusion is made that using SHF radiation for technological fuel preheating is essential. An approach has been developed that improves low-temperature properties of diesel fuels and increases engine operation efficiency under severe climatic conditions by introducing a multifunctional additive. The additive will enable a significant decrease in fuel consumption under low-temperature operating conditions and a complex improvement of fuel properties.
\end{abstract}

\section{Introduction}

Nowadays, rapid depletion of energy resources and rise in their cost, as well as increased environmental problems necessitates building the urban environment not only in terms of the presence of infrastructure, but also considering its management competences. It is possible to ensure effective control by using modern innovative technologies based on the «Smart city» system, which provide modern life quality. Such technologies shall provide for an economical and environmentally friendly use of municipal life support systems.

a Corresponding author: tkcc@list.ru 
In a «smart» city, transport based on the intelligent transport system plays a special role. GOST R ISO 14813-1-2011 «Intelligent transport systems (ITS). Reference model architecture(s) for the ITS sector», Part 1 «ITS service domains, service groups and services» provides requirements for vehicle design. Their design must ensure the improvement of safety, reliability and vehicle operation efficiency by cautioning the users or managing the systems or units of vehicles. It should be noted that the quality of fuels ultimately influences the environmental safety and operating efficiency of vehicles. It would be impossible to achieve them with low-quality fuels, even if the design solutions were optimal.

Vehicle efficiency means the ability to perform the required work under given conditions while minimizing the energy costs and exhaust gas emissions.

Thus, «smart» city vehicles must manage their systems and aggregates in order to reduce fuel consumption and exhaust gas emissions.

As far as Russia is concerned, the proportion of urban population is about $75 \%$; the country is at 4 th position in the world by the number of cities with a million-plus population (15 cities), the first three being China, India and Brazil. At the same time Russia is the coldest country in the world. Therefore, designing vehicles for a «smart» city should take into account the above-mentioned features, namely a considerable time of operation at low air temperatures that significantly change fuel consumption and exhaust gases emissions [1]. In addition, vehicles react differently to the changes of environment, i.e., they are differently adapted to variable operating conditions. It is necessary to develop approaches and devices to improve the adaptability of vehicles to low-temperature operating conditions $[2,3]$. This problem can be solved by applying operational and organizational measures, developing additional units and aggregates that improve the adaptability level and using high-quality motor fuels adapted to low-temperature conditions.

\section{Methods of vehicle adaptation to low-temperature conditions}

The main directions of research to improve the efficiency and adaptability of vehicles to low-temperature conditions are related mainly to the improvement of structures, technological parameters of transport, technological process organization, as well as with fuel quality modification. The main directions of current research in energy efficiency for the transportation facilities are: optimization of the structure and improvement of the characteristics of the vehicle fleet (including the design of engines and vehicles themselves), improvement of the maintenance system, road network and traffic management, reduction of the negative impact of climatic conditions, improvement of lowtemperature fuel characteristics, both by oil refining methods and application of the fuel additives.

Increasing the adaptability of vehicles to variable low-temperature operating conditions can be an effective method of increasing their efficiency. A considerable amount of research [4-7] is devoted to the issues of improving the adaptability, which attract the interest of different scientific groups.

Nowadays, effective methods of vehicle adaptation to low ambient temperature conditions are not so commonly applied in Russia. The known methods of technological fluids (TF) preheating (preheaters, tape preheaters, thermoelectric heaters, etc.) are used and studied. However, more advanced methods of preheating, in particular heating by super-high frequency (SHF) currents, which is one of the perspective methods of vehicles adaptation to low-temperature operating conditions, are practically not applied. The authors witness an increased interest in studying the capabilities of hydrocarbon preheating by SHF currents in vehicles and technological machines (pipeline, railroad transport); however, 
there is no complex method of applying heat to various TF in a vehicle by means of SHF radiation.

\subsection{Using SHF radiation for technological fluids preheating}

A reserve of improving the transport operation efficiency is creating a neural network control system of preheating and maintaining the optimum temperature of TF. In the recent past, it was impossible to solve this problem, since there was no componential base of devices capable of instantly getting into gear and providing a uniform heating of the full volume of TF. Application of SHF radiation for such purposes allows solving the given objectives.

The issues of applying SHF radiation in technical systems, including transport, are covered in [8-11]. Analysis of available publications shows that as for the efficiency of warming-up and, to a greater extent, maintaining the optimum temperature of TF the given method is the most competitive. However, up to now the following sequence has been poorly studied: treatment of the TF (fuel - regular, gas; oil; cooling liquid) - change of its physical and chemical properties - influence of the changed TF on the parameters of the internal combustion engine (ICE) working process (starting qualities, fuel consumption, environmental parameters). Meanwhile, this process particularly presents a wide interest, since the influence on TF at molecular and atomic levels can lead to any sort of changes in their physical and chemical properties. Thus, research in the given area will be the basis for identification of all qualitative changes in TF and evaluation of positive and negative sides of the given effect on TF.

The research focuses on developing a technique and device to improve vehicle efficiency by means of preheating that would not have thermal inertia, with the liquid heated instantaneously in the entire volume using less energy compared to conventional heating methods. Preheating by SHF radiation satisfies these conditions. After being treated with the SHF electromagnetic field, dielectric molecules are polarized and perform mechanical oscillations producing the energy which, due to intermolecular friction, is converted into heat and heats the dielectric. Heating takes place in the SHF electromagnetic field within the range of frequencies determined by the process requirements based on the volume of TF, its physical and chemical properties, initial and final heating temperature and other factors. The frequency of electromagnetic oscillations and, as its function, the wave length of the electromagnetic field is selected (calculated, determined experimentally) so as to be smaller than the geometric size of a compartment that contains TF. In this case, the electromagnetic field inside the compartment has a wave nature and repeatedly passes through the liquid, being reflected from the walls. However, SHF treatment of TF will inevitably lead to a change in its physical and chemical properties, since exposure occurs at the atomic level, which will affect its performance in the ICE. In this regard, we need to understand what changes occur in a particular fluid (changes in oil viscosity, its detergent power, flash point, chilling point, octane number, etc.).

The next step of the research must involve evaluating the ICE performance on the modified fuels, which results in development of the recommendations on how to treat a certain fluid or whether such treatment is allowable at all. In case of a complex positive result we need to develop comprehensive approaches to creating a system of preheating and maintaining the optimum temperature of TF at the given level on the example of preheating gaseous fuel with SHF radiation when it enters the engine. For the machinery to operate efficiently it is necessary to maintain its TF temperature at the optimum level. The optimum TF temperature ensures the lowest wear of units and aggregates, reduces fuel consumption, decreases exhaust gas emissions, etc. The optimum oil temperature (engine, reduction 
gearbox) improves lubrication of friction members by improving oil penetration into a gap between contacting surfaces. The optimum hydraulic oil temperature (hydraulic system, hydraulic cylinders, shock absorbers) reduces the risk of failure of units operating under high pressure due to the optimum oil viscosity. The optimum temperature of the cooling liquid in the internal combustion engine provides the best conditions for carburation and combustion of fuel in the cylinders of the engine by improving fuel-air mixing process. The optimum fuel temperature improves carburation, increases the cycle temperature and, as a result, fuel combustion efficiency, and reduces fuel consumption and exhaust gas emissions at idle speed. The optimum washing fluid temperature ensures the washer efficiency and reduces the risk of accidents caused by a contaminated windshield or headlights of the vehicle. To be able to achieve the optimum TF temperature a unit, aggregate or system should be warmed up to this state. The problem of warming up the vehicle engine is particularly urgent at low air temperatures. This problem is related to a complex start of the power plant, therefore, additional means of starting and warming the engine together with the systems, units and aggregates up to the operating temperature are becoming more commonly used. Currently used preheaters operate on a general principle of heating the liquid by heat transfer from the heated body (electric heater, exhaust gas heat exchanger, cooling liquid heat exchanger). This principle has a long response time and does not allow the given fluid temperature to be maintained. Devices that provide this method, as mentioned earlier, have a greater metal content, are not reliable and require additional costs to ensure their functionality. Thus, it is essential to develop a method and device that will provide rapid heating of fluid and maintain the fluid temperature at a certain optimum level.

\subsection{Motor fuel adaptation to low-temperature conditions}

In Russia the actual quality of motor fuels produced by the oil refining industry significantly lags behind modern European standards. A comprehensive solution to the problem requires a drastic change in the ratio of refining processes towards developing modern processes of improving fuel quality, which is not possible without multi-billion investments [12]. Different aspects of improving the quality of motor fuels by refining methods are presented in various studies [12-15].

In view of insufficient volume of winter diesel fuels manufactured in Russia there is an enormous over-expenditure of fuel, due to the unavoidable use of summer diesel fuels in winter. An improvement of the low-temperature properties of diesel fuels, a decrease in cloud point, pour point and cold filter plugging point in particular, will considerably increase the efficiency of diesel fuel at low temperatures. The oil refining industry in Russia is limited in its ability to considerably and quickly change the ratio of the produced summer, winter and Arctic grades of diesel fuels. That is why the most realistic method of fuel adaptation to low-temperature operating conditions is the application of additives improving the low-temperature properties of fuel. Thus, great volumes of diesel fuel consumption at significant concentration of the known depressants required for obtaining a significant decrease in pour point and cold filter plugging point considerably limit the application of these additives in diesel fuels. It is necessary to develop an additive that will have a significant impact when its concentration in the fuel is very low. Thus, the application of a multifunctional additive that improves the properties of diesel fuels and characteristics of engines is the most perspective.

It should be noted that improving motor fuel properties by means of additives [16-20] has a great performance potential, which is demonstrated by a considerable range of additives and numerous patents on the global market. Certain properties of motor fuels 
(lubricating, detergent) can only be modified with the help of additives, and are not provided by changing the refining industry technology.

\section{Results and discussion}

\subsection{Influence of SHF radiation on physical and chemical parameters of diesel fuels}

The first stage of the experimental research was to determine the changes in physical and chemical parameters of diesel fuel after exposure to SHF radiation.

Diesel fuel (winter grade) complying with the requirements of standards was divided into $100-\mathrm{ml}$ probes. Each probe was exposed to SHF radiation for a different period of time. In total, 20 probes of $100 \mathrm{ml}$ each were tested. The total amount of fuel obtained during one investigation -2 liters. Table 1 provides the initial data.

Further on, the fuel was studied by assessing the following parameters: kinematic viscosity, density, flash point in a closed cup.

Table 1. Initial data

\begin{tabular}{|c|c|c|c|}
\hline Number of probe & Exposure time, sec & Magnetron capacity, W & Frequency, $\mathbf{G H z}$ \\
\hline 1 & 0 & 850 & 2.4 \\
\hline 2 & 180 & 850 & 2.4 \\
\hline 3 & 300 & 850 & 2.4 \\
\hline 4 & 480 & 850 & 2.4 \\
\hline
\end{tabular}

Kinematic viscosity was studied according to GOST 33-2000 «Petroleum products. Transparent and opaque liquids. Determination of kinematic viscosity and calculation of dynamic viscosity». The standard determines a method for determination of kinematic viscosity of liquid petroleum products, transparent and opaque liquids by measuring the time it takes for a certain volume of liquid to flow under gravity through a calibrated glass capillary viscometer.

Density was studied according to GOST 3900-85 «Petroleum and petroleum products. Methods for determination of density». The method is used to determine density of petroleum and petroleum products by an oil hydrometer. Essentially, the method involves submerging the oil hydrometer in the test product, taking readings on the hydrometer scale at a test temperature and converting the results into density at a temperature of $20^{\circ} \mathrm{C}$.

Flash point in a closed cup was studied according to GOST 6356-75 «Petroleum products. Method of test for flash point in a closed cup». It establishes a method for determination of flash point in a closed cup. Essentially, the method involves determining the lowest temperature at which under test conditions above the combustible substance's surface a mixture of fumes and vapors with air is formed. It is capable of flashing in the air from a source of ignition, but their rate of formation is still insufficient for the subsequent combustion. For this purpose, the test product is heated in a closed cup at a constant rate with continuous stirring and tested for flash at certain temperature intervals.

The study results are given in Table 2 .

Table 2. Results of studying the impact of SHF radiation on physical and chemical parameters of diesel fuel

\begin{tabular}{|c|l|c|c|c|c|}
\hline № & \multicolumn{1}{|c|}{ Test parameter } & Probe 1 & Probe 2 & Probe 3 & Probe 4 \\
\hline 1 & Kinematic viscosity, $\mathrm{mm}^{2} / \mathrm{s}$ & 3.21 & 3.16 & 3.13 & 3.04 \\
\hline 2 & Density, $\mathrm{kg} / \mathrm{m}^{3}$ & 824 & 821 & 820 & 815 \\
\hline
\end{tabular}




\begin{tabular}{|l|l|l|l|l|l|}
\hline 3 & Flash point in a closed cup, ${ }^{\circ} \mathrm{C}$ & 36 & 33 & 30 & 30 \\
\hline
\end{tabular}

The results lead to the following conclusions.

Exposure of fuel to SHF radiation reduces the content of both aromatic and naphthenic and heavy paraffinic hydrocarbons. The authors can also assume that viscosity decreased due to changes in the molecular structure. There was a decrease in the number of rings in the molecules of naphthenic and aromatic hydrocarbons; the hydrocarbon chain of paraffinic hydrocarbons and the length of a radical of naphthenic and aromatic hydrocarbons became smaller. All this indicates the decomposition of high molecular weight hydrocarbons. This is also supported by the results of determining the flash point in a closed cup. The lower the flashpoint, the more light hydrocarbons (low molecular weight paraffins) it contains.

\subsection{Influence of SHF radiation on the engine output parameters}

The next step of the research involved evaluating the ICE performance on fuels treated with SHF radiation. Tests were conducted on a diesel generator SDMO T9KM with a diesel engine Mitsubishi S3L2 SD. Table 3 presents main technical characteristics of the diesel generator. The test parameters were: fuel consumption per hour, $\mathrm{kg} / \mathrm{h}$; percentage of $\mathrm{NO}_{\mathrm{x}}$ in exhaust gases, \% vol.; smoke from the exhaust, \%.

Factors considered during tests: fuel temperature, $+20^{\circ} \mathrm{C}$; air temperature, $+20{ }^{\circ} \mathrm{C}$; atmospheric pressure, $750 \mathrm{~mm}$ of mercury; engine load, $70 \%$ of the nominal; rotational rate, $1500 \mathrm{~min}^{-1}$. The values of fuel consumption were recordered from the dashboard of the diesel generator.

The $\mathrm{NO}_{\mathrm{x}}$ percentage in the exhaust gases was measured using a gas analyzer GIAM29M-3, which technical characteristics are shown in Table 4.

The smoke from the exhaust was determined using an opacimeter META-01MP 0.1 LTK, which technical characteristics are shown in Table 5 . The test results are shown in Table 6.

Table 3. Technical characteristics of the diesel generator

\begin{tabular}{|l|l|}
\hline Characteristics & Values \\
\hline Capacity, $\mathrm{kW}$ & 8.6 \\
\hline Cooling type & liquid \\
\hline Nominal speed, $\mathrm{min}^{-1}$ & 1500 \\
\hline Make of AC generator & Mecc Alte ECP 3-3L/4 \\
\hline Fuel consumption 1/hour (at 70\% load) & 2.4 \\
\hline Noise level & $60.4 \mathrm{~dB}$ \\
\hline
\end{tabular}

Table 4. Technical characteristics of gas analyzer GIAM-29M-3

\begin{tabular}{|l|l|}
\hline Characteristics & Values \\
\hline Type of gas analyzer & portable \\
\hline Way of probe sampling & forced \\
\hline Principle of action & electrochemical \\
\hline NO measuring range, $\%$ vol. & $0-0.5$ \\
\hline Limit of the tolerable basic reduced error, $\mathrm{NO} \%$ : & 10 \\
\hline Ambient temperature, ${ }^{\circ} \mathrm{C}$ & from 0 to +45 \\
\hline
\end{tabular}

The diesel fuel treatment led to a reduction in the smoke from the exhaust to $15 \%$. This can be explained by a decrease in the number of areas with a lack of oxygen because of improved mixture formation that was caused by a decrease in the viscosity and density of the fuel. 
There is a reduction in the nitrogen oxide emissions to $30 \%$, which is due, among other things, to a reduction of the fuel flash point in a closed cup. This corresponds to a decrease in the self-ignition temperature of the fuel and an improvement of combustion at a lower fuel density. The fuel burns more uniformly, without temperature peaks.

The reduced fuel consumption down to $7 \%$ may indicate an improvement in the process of mixture formation and combustion, due to an increased amount of light hydrocarbon fractions.

Table 5. Technical characteristics of the opacimeter META-01MP 0.1 LTK

\begin{tabular}{|l|l|}
\hline Characteristics & Values \\
\hline Type of device & portable \\
\hline Smoke measurement range in terms of absorption coefficient K, not less than, $\mathrm{m}^{-1}$ & $0-\infty$ \\
\hline Smoke measurement range in terms of attenuation coefficient $\mathrm{N}, \%$ & $0-100$ \\
\hline Absolute limit of error at absorption coefficient of $1.6-1.8 \mathrm{~m}^{-1}$ not greater than, $\mathrm{m}^{-1}$ & \pm 0.05 \\
\hline Nominal scale point of the least category for absorption coeff., $\mathrm{m}^{-1}$ & 0.01 \\
\hline Nominal scale point of the least category for attenuation coeff., $\%$ & 0.1 \\
\hline Photometric base, $\mathrm{m}$. & 0.1 \\
\hline Automatic adjustment of smoke readings by the temperature of exhaust gases & enabled \\
\hline Automatic zero adjustment & enabled \\
\hline
\end{tabular}

Table 6. Results of studying the impact of SHF radiation on the engine output parameters

\begin{tabular}{|c|c|c|c|c|c|}
\hline № & Test parameter & Probe 1 & Probe 2 & Probe 3 & Probe 4 \\
\hline 1 & Fuel consumption per hour, $\mathrm{kg} / \mathrm{h}$ & 2.38 & 2.31 & 2.24 & 2.21 \\
\hline 2 & Percentage of NO in exhaust gases, \% & 0.03 & 0.03 & 0.026 & 0.023 \\
\hline 3 & Smoke from the exhaust, \% & 60 & 58 & 55 & 52 \\
\hline
\end{tabular}

\subsection{Improvement of low-temperature properties of diesel fuels using additives}

The impact of depressants is the result of adsorption of additive's molecules on the surface of a paraffin crystal that prevents its further growth. Thus, smaller crystals are formed and their coalescence, leading to the formation of three-dimensional paraffin structure causing oil solidification, is less likely to occur. For diesel engine operation the most important indicator of low-temperature properties is a cold filter plugging point; however, a large difference between the cold filter plugging point and cloud point is ineffective, as small crystals passing through the filter are deposited, disrupting fuel supply.

The influence of depressants on the cloud point is possible if the depressant molecule when reacting with alkane molecules with a high melting point prevents the formation of paraffin crystal nuclei.

The acting mechanism of depressants makes a lot of substances depressant-active if their molecules contain a fragment with alkane properties (long unbranched alkyl radical) and a polar group or a group radically different in structure: alkylnaphthalene, soaps of polyvalent metals, relatively low molecular weight polymethacrylates (molecular weight $\sim 17000$ ) containing n-alkyl radicals $\mathrm{C}_{12} \div \mathrm{C}_{18}$, low molecular weight copolymer of ethylene and vinyl acetate and others. One of the most effective depressant additives, named Keroflux 5486, is manufactured by BASF. At concentration $0.05 \%$ it decreases the pour point of summer grades of diesel fuels by $15-18^{\circ}$ and the cold filter plugging point by 14 $16^{\circ}$.

A multifunctional additive [RCOO $]_{2} \mathrm{Me}$, where $\mathrm{R}=\mathrm{C}_{9} \mathrm{H}_{19} \div \mathrm{C}_{15} \mathrm{H}_{31}$, was developed, providing a comprehensive positive effect on the properties of the fuels used [18]. Investigations of the influence of the additive on the low-temperature properties of diesel fuels have been conducted. 
At extremely low concentrations in diesel fuel $[\mathrm{RCOO}]_{2} \mathrm{Me}$ significantly (by $8-9^{\circ}$ ) reduces the cold filter plugging point (Table 7).

Table 7. Impact of $[\mathrm{RCOO}]_{2} \mathrm{Me}$ at concentrations $27.75 \mathrm{mg} / \mathrm{kg} / 18.5 \mathrm{mg} / \mathrm{kg}$ in diesel fuel on the low-temperature properties of fuels

\begin{tabular}{|l|c|c|c|}
\hline \multirow{2}{*}{ Diesel fuel } & \multicolumn{3}{|c|}{ Reduction in temperature, ${ }^{\circ} \mathbf{C}$} \\
\cline { 2 - 4 } & cloud point & pour point & cold filter plugging point \\
\hline Sample I (pour point $-7^{\circ}$ ) & $-4 /-3$ & $-9 /-8$ & $-8 /-9$ \\
\hline Sample II (pour point $-14^{\circ}$ ) & $0 / 0$ & $-2 / 0$ & $-9 /-8$ \\
\hline
\end{tabular}

The obtained results based on existing ideas about the low-temperature properties of fuels are explained by the increase in dispersion of the released paraffin crystals due to blocking the crystal growth by adsorption of the additive's surfactant molecules on their surface.

The additive significantly - by up to $10 \%$ - reduces the diesel fuel consumption at low ambient temperatures, both by improving the low-temperature properties of fuels, and as a result of eliminating carbonization in the engine [19]. The additive also has anti-wear properties, improving the lubricating ability of diesel fuel up to $25 \%$, which significantly reduces the wear of plunger pairs in high-pressure fuel pumps of diesel engines. At the same time, the environmental performance of diesel engines significantly improves: $\mathrm{CO}$ emissions decrease by $15-17 \%$, nitrogen oxide emissions - by $20-22 \%$, hydrocarbons emissions - by $35-37 \%$, soot emissions - by up to $40-50 \%$. It should be noted that the use of additives does not result in the formation of any additional toxic substances in exhaust gases that have not been previously observed.

\section{Conclusions}

Treatment of diesel fuel with SHF radiation improves its environmental performance and reduces fuel consumption.

The results obtained are the basis for the development of a neural network control system of maintaining the optimum temperature of diesel fuel in a vehicle for the «smart city» system that improves its efficiency and environmental safety due to neural network control of units and aggregates. Neural network control will enable the improvement of the adaptability of vehicles to variable low-temperature operating conditions according to fuel consumption and environmental indicators.

Application of the proposed multifunctional additive improves the low-temperature properties of diesel fuel and has a complex positive impact on the diesel fuel properties and the state of engines. The additive enables a significant decrease in fuel consumption under low-temperature operating conditions and improves the environmental safety of vehicle operation.

\section{Acknowledgement}

This research was supported by Act 211 Government of the Russian Federation, contract № 02.A03.21.0006.

\section{References}

1. N. Karnaukhov, L. Reznik, V. Holyavko, Adv. Transport, 6, 439-443 (2000)

2. I. Anisimov, A. Ivanov, E. Chikishev, D. Chainikov, L. Reznik, WIT Trans. Ecol. Envir., 190 (1), 685-695 (2014) 
3. J.A. Ertman, S.A. Ertman, I.A. Anisimov, D.A. Chainikov, Y.M. Chikishev, Research Journal of Pharmaceutical, Biological and Chemical Sciences, 6 (1), 1761-1770 (2015)

4. B. Torregrosa-Jaime, F. Bjurling, J.M. Corberan, F. Di Sciullo, J. Paya, Appl. Therm. Eng., 75, 45-53 (2015)

5. C. Bauer, J. Hofer, H.J. Althaus, A. Del Duce, A. Simons, Appl. Energ., 157, 871-883 (2015)

6. A.P. Roskilly, R. Palacin, J. Yan, Appl. Energ., 157, 563-566 (2015)

7. E. Magaril, L. Reznik, Urban Transport and the Environment II, 149-154 (1996)

8. M. Novotný, K. Šuhajda, J. Sobotka et al., Wood Res-Slovakia, 59 (3), 389-400 (2014)

9. D. Nowak, M. Stachowicz, K. Granat, M. Pigiel, Metalurgija, 52 (2), 211-214 (2013)

10. K. Granat, B. Opyd, D. Nowak, M. Stachowicz, G. Jaworski, Arch. Metall. Mater., 58 (3), 919-922 (2013)

11. A. Arshanitsa, Y. Akishin, E. Zile et al., Renew. Energ., 91, 386-396 (2016)

12. E. Magaril, WIT Trans. Ecol. Envir., 190 (2), 821-832 (2014)

13. R.R. Shiriyazdanov, U.S. Rysaev, E.A. Nikolaev et al., Chem. Tech. Fuels Oil+, 44 (5), 295-297 (2008)

14. P.R. Robinson, in: Practical Advances in Petroleum Processing, 1, 1-78 (New York, 2006)

15. A. Stanislaus, A. Marafi, M.S. Rana, Catal. Today, 153 (1-2), 1-68 (2010)

16. J. Bennett, in: Alternative fuels and advanced vehicle technologies for improved environmental performance. Towards zero carbon transportation, 165-194 (2014)

17. A.M. Danilov, Chem. Tech. Fuels Oil+, 47 (6), 470-484 (2012)

18. E. Magaril, WIT Trans. Ecol. Envir., 147, 373-384 (2011)

19. E. Magaril, International Journal of Sustainable Development and Planning, 8 (2), 231-245 (2013)

20. Srivastava, J. Hancsók, Fuels and fuel-additives (New Jersey, 2014) 